\title{
Synthesis of control system of recuperation of braking energy to supply grid for Metropolitan
}

\author{
V. N. Anosov \\ Novosibirsk State Technical University \\ Novosibirsk, Russian Federation \\ anosovvn@gmail.com
}

\author{
V. M. Kaveshnikov \\ Novosibirsk State Technical University \\ Novosibirsk, Russian Federation \\ vldi@yandex.ru
}

\author{
E. A. Livanova \\ Novosibirsk State Technical University \\ Novosibirsk, Russian Federation \\ immersamstag@mail.ru
}

\begin{abstract}
The article is devoted to synthesis of an optimal regulator of the process of recovery of the braking energy of trains using an AC traction electric drive. The optimality criteria, mathematical description of the system of energy recovery, suitable for the maximum principle of $L$. S. Pontryagin application, were developed; the structure and parameters of an optimal controller were obtained.
\end{abstract}

Keywords-traction electric drive, recuperation energy, recuperator, the criterion of optimality, maximum principle, optimal regulator.

\section{INTRODUCTION}

The metro is the most promising form of mass urban transport, which fully meets the modern requirements for carrying capacity, the speed of communication, and ecology. Modern trains of the subway have traction electric drives on the basis of squirrel cage induction motors powered by an independent inverter. These trains have axial loads up to 12 tons/axle, the starting acceleration up to $1.2 \mathrm{~m} / \mathrm{sec}^{2}$, the regenerative braking throughout the speed range and require up to $70 \%$ of electricity, consumed by metro. So, the solution of the problem aimed to substantially reduce energy consumption for traction in the underground is of great importance for the economy of the region, which makes this task very urgent.

A method of saving on metro trains without the use of stored energy is described in [1]. The transfer of the braking energy of trains in the network is "bypassing" the traction rectifier through the energy recuperator from DC to AC. It is shown that the proposed method is more effective than other known conservation measures in traction drives (TED).

Fig. 1 shows a simplified single-phase diagram of energy recovery, including only the elements of TED and a traction power substation, involved in the transmission of the flow of energy from braking trains in the grid.

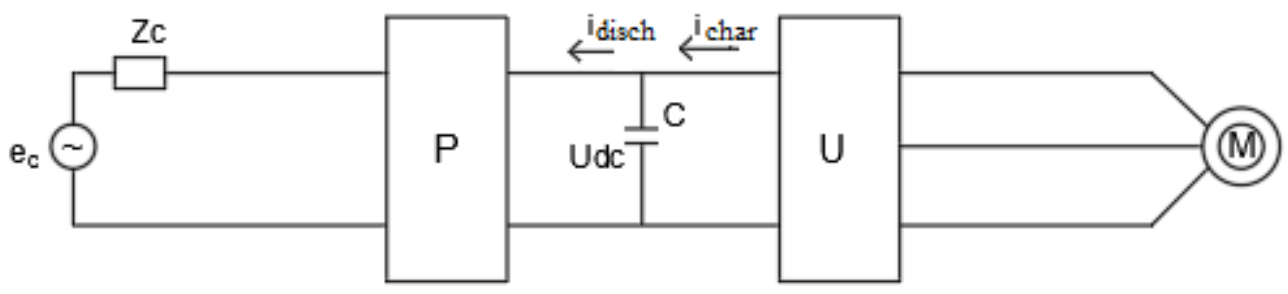

Fig.1. A simplified single-phase diagram of the electric traction drive with network elements in the regenerative braking mode.

In figure 1 , there are the following notations: $\mathrm{e}_{\mathrm{g}}$ - grid $\mathrm{EMF} ; \mathrm{Z}_{\mathrm{g}}$ - the impedance of a grid from the $\mathrm{AC}$ side of recuperator $\mathrm{P} ; \mathrm{C}$ - capacitor in the $\mathrm{DC}$ link of the frequency converter with inverter $\mathrm{U} ; \mathrm{M}$ - the traction asynchronous motor.

The nominal voltage in the DC link is determined by the output voltage of the traction rectifier connected to AC power EMF.
Developers of the automatic control system (ACS) always have the task of selecting one optimal law, which is the most efficient in a certain sense, from the set of possible control laws. The performance indicator takes the form of quality functional $\mathrm{J} \longrightarrow \min (\max )$, which is the optimality criterion. The choice of an optimality criterion is determined by the physical meaning of the system. 
Under the braking mode, the TED works as a generator, the part of the kinetic energy of the train is fed to the DC link, and capacitor $\mathrm{C}$ is charged by the amount:

$$
\Delta \mathrm{U}_{\text {char }}(\mathrm{t})=1 / \mathrm{R}_{\text {char }} * \mathrm{C} * \int \mathrm{i}_{\text {char }}(\mathrm{t}) \mathrm{dt} \text {. }
$$

At the same time, if $\Delta \mathrm{U}_{\text {char }}(\mathrm{t})$ exceeds a certain value, recuperator $\mathrm{P}$ starts and the energy of the capacitor with current $i_{\text {disch }}(t)$ through $P$ is transmitted to the network. The capacitor is discharged by the amount:

$$
\Delta \mathrm{U}_{\text {disch }}(\mathrm{t})=1 / \mathrm{R}_{\text {disch }} * \mathrm{C} * \int \mathrm{i}_{\text {disch }}(\mathrm{t}) \mathrm{dt} .
$$

In (1) and (2), $\mathrm{i}_{\text {char }}(\mathrm{t})$ and $\mathrm{i}_{\text {disch }}(\mathrm{t})$ are respectively the currents of charge and discharge of the capacitor; and $\mathrm{R}_{\text {char }}$, $\mathrm{R}_{\text {disch }}$ are respectively the equivalent resistance circuits of the charging and discharging of the capacitor.

The magnitude of recovery current $i_{r}$ is determined by voltage $\mathrm{Ud}(\mathrm{t})$, control signal of recuperator $\mathrm{Uy}$ and equivalent grid parameters $\mathrm{e}_{\mathrm{g}}, \mathrm{z}_{\mathrm{g}}$.

The voltage on the capacitor in the regeneration process is:

$$
\mathrm{Ud}=\mathrm{Ud}_{0}+\Delta \mathrm{U}_{\text {char }}(\mathrm{t})-\Delta \mathrm{U}_{\text {disch }}(\mathrm{t})=\mathrm{Ud}_{0}+\Delta \mathrm{U}(\mathrm{t}),
$$

where $\mathrm{Ud}_{0}=$ const is the voltage on the DC buses in the mode of nominal thrust;

$\Delta \mathrm{U}(\mathrm{t}) \geq 0$ is the change in the voltage on the DC buses in the braking mode of electric trains.

It is obvious that ceteris paribus, the optimal transmission of the braking energy will be in the case of $\Delta \mathrm{U}(\mathrm{t})=0$, when the charge on the capacitor does not change, i.e. the current through the capacitor is 0 . However, existent instability of the braking process because of a changing rate of braking commands of the driver and variability of resistance to movement due to changes in profile path in the braking process, to maintain the value of $\Delta \mathrm{U}(\mathrm{t})$ close to 0 , appropriate control of the recuperator $\mathrm{U}_{\mathrm{u}}(\mathrm{t})$ according to some rule, can be considered optimal.

To maintain a constant value of $\mathrm{Ud}$, in [2], the negative feedback on this value is used; the proportional controller generates the control signal for the recuperator. As the results show, such control is far from optimal.

In the present work, the integral criterion is used to synthesize the optimal controller, i.e.:

$$
\mathrm{J}=\int \Delta \mathrm{U}^{2}(\mathrm{t}) \mathrm{dt} \longrightarrow \min .
$$

The criterion gives the smoothing of the $\Delta \mathrm{U}(\mathrm{t})$ fluctuations during braking.

\section{THE MATHEMATICAL DESCRIPTION OF TEP DURING RECUPERATION}

The application of existing analytical optimization methods, optimization of control systems requires mathematical description of the object of control, reflecting its main

The equation of the first order is essentially nonlinear. Its linearization to simplify the optimization problem will lead to functions under reasonable assumptions and simplifications, which are the result of a compromise between the desire for precision reflection properties of the object and the need to simplify its mathematical description:

- taking into account only those elements of the TEP, which are involved in the process of recovery of braking energy;

- internal processes in the recuperator and the inverter are not taken into account;

- the equivalent resistance of $\mathrm{Z}_{\mathrm{g}}$ and $\mathrm{EMF}$ is considered permanent;

- $\mathrm{R}_{\text {char }}$ and $\mathrm{R}_{\text {disch }}$ are permanent;

- the value of $\mathrm{Ud}_{0}$ in the process of recovery is not changed;

- the magnitude of the charging current $i_{\text {char }}=I_{\text {char }}=$ const in interval $\left(0 ; t_{\mathrm{T}}\right)$, defined by the mode of reference of the train;

- energy losses in the elements of the TED are not taken into account;

- grid frequency is constant;

- energy losses in the recuperator are not taken into account;

- control characteristic of the recuperator $\mathrm{e}_{\mathrm{R}}=\mathrm{U}_{\mathrm{u}} * \mathrm{Ud}^{*}$ (at $\mathrm{Ud}$ $=$ const ) is considered to be linear;

- system variables on the AC side is represented by the rms values.

- the inertia in the DC link created by the capacitor; the inertia of the other elements of the system are not taken into account.

Taking into account the accepted assumptions, the system of equations, describing the control object, has the form:

$$
\begin{aligned}
& \mathrm{d} \Delta \mathrm{U}(\mathrm{t}) / \mathrm{dt}=\left(1 / \mathrm{R}_{\text {char }} * \mathrm{C}\right) * \mathrm{I}_{\text {disch }}\left(1 / \mathrm{R}_{\text {disch }} * \mathrm{C}\right) * \mathrm{i}_{\text {disch }}(\mathrm{t}) ; \\
& \Delta \mathrm{U}_{\text {char }}(\mathrm{t})-\Delta \mathrm{U}_{\text {disch }}(\mathrm{t})=\Delta \mathrm{U}(\mathrm{t}) \\
& \mathrm{I}_{\mathrm{c}}(\mathrm{t})=\left(\mathrm{e}_{\mathrm{c}}-\mathrm{e}_{\mathrm{r}}(\mathrm{t})\right) / \mathrm{z}_{\mathrm{c}} ; \mathrm{e}_{\mathrm{r}}(\mathrm{t})=\mathrm{U}_{\mathrm{u}}(\mathrm{t}) * \mathrm{Ud}(\mathrm{t}) ; \\
& \Delta \mathrm{U}_{\text {char }}(\mathrm{t})=1 /\left(\mathrm{R}_{\text {char }} * \mathrm{C}\right) * \mathrm{i}_{\text {char }} * \mathrm{dt} ;
\end{aligned}
$$

$$
\begin{aligned}
& \Delta \mathrm{U}_{\text {disch }}(\mathrm{t})=1 /\left(\mathrm{R}_{\text {disch }} * \mathrm{C}\right) * \int \mathrm{i}_{\text {disch }}(\mathrm{t}) * \mathrm{dt} \\
& \mathrm{d} \Delta \mathrm{U}(\mathrm{t}) / \mathrm{dt}=1 /\left(\mathrm{R}_{\text {char }} * \mathrm{C}\right) * \mathrm{I}_{\text {char }}-1 /\left(\mathrm{R}_{\text {disch }} * \mathrm{C}\right) * \mathrm{i}_{\text {disch }}(\mathrm{t}) ;
\end{aligned}
$$

$\mathrm{Ud}=\mathrm{Ud}_{0}+\Delta \mathrm{U}$.

After appropriate transformations, one gets:

$$
\mathrm{d} \Delta \mathrm{U} / \mathrm{dt}=\mathrm{A}-\mathrm{B} * \mathrm{U}_{\mathrm{u}}+\mathrm{F}^{*} \mathrm{U}_{\mathrm{u}}{ }^{2}+\mathrm{D} * \Delta \mathrm{U}(\mathrm{t}) * \mathrm{U}_{\mathrm{u}}{ }^{2},
$$

where $\mathrm{A}=\mathrm{I}_{\text {char }} / \mathrm{R}_{\text {char }} * \mathrm{C} ; \mathrm{B}=\mathrm{e}_{\mathrm{g}} / \mathrm{R}_{\text {disch }} * \mathrm{C} * \mathrm{Z}_{\mathrm{g}} ; \mathrm{F}=\mathrm{Ud}_{0} /$ $\mathrm{R}_{\mathrm{char}} * \mathrm{C} * \mathrm{Z}_{\mathrm{g}} ; \mathrm{D}=1 / \mathrm{R}_{\mathrm{disch}} * \mathrm{C} * \mathrm{Z}_{\mathrm{g}}$.

the loss of the most important properties of the object. In addition, linearization of the multiplicative nonlinearities in 
the right-hand side of the equation involves the consideration of system properties only "in the least", whereas the optimization in this case requires correction of the behavior of the object "in the large". This approach will further limit the possibility of choice of the optimization method, but allows analytical solutions.

The problem in the exact statement can be solved using calculus of variations. The maximum principle of L. S. Pontryagin is used [3-6]. The maximum principle, well suited for continuous systems, are not limited by the nonlinearities of an object or works under the integral control constraints.

On the other hand, in the general case, the maximum principle gives necessary conditions for the optimum, however, if the control process is linear and subject to additive control functions, it provides not only necessary but also sufficient conditions for optimal control.

Therefore, let us further consider the case of a linearized object.

If one assumes that the value of $\mathrm{Ud}_{0}=\mathrm{U}_{\mathrm{CN}} \cdot \mathrm{K}_{\mathrm{B}}$, where $\mathrm{U}_{\mathrm{CN}}$ nominal value of voltage; $K_{B}$ - coefficient of transfer of an uncontrolled rectifier, when $\mathrm{U}=\Delta \mathrm{U}_{\text {char }}-\Delta \mathrm{U}_{\text {disch }}>0$, on the $A C$ side, recuperating current occurs. The current will be transmitted by the braking energy to the grid.

With constant $\mathrm{e}_{\mathrm{g}}$ and $\mathrm{z}_{\mathrm{g}}$ recuperating current and, therefore, the discharge current of capacitor $i_{\text {disch }}(t)$ will be determined by value $\Delta \mathrm{U} \cdot \mathrm{U}_{\mathrm{u}} \cdot \mathrm{K}_{\mathrm{R}}$, where $\mathrm{K}_{\mathrm{R}}$ is a constant, depending on the design of the recuperator and grid parameters $\mathrm{e}_{\mathrm{c}}$ and $\mathrm{z}_{\mathrm{c}}$, i.e:

$$
\mathrm{i}_{\text {char }}(\mathrm{t})=\Delta \mathrm{U} \cdot \mathrm{U}_{\mathrm{u}} \cdot \mathrm{K}_{\mathrm{R}} \text {. }
$$

In turn:

$$
\begin{aligned}
& \Delta \mathrm{U}^{\prime}=\mathrm{A}^{\prime}-\int_{\mathrm{t}}\left(\mathrm{i}_{\text {disch }} / \mathrm{R}_{\mathrm{char}} * \mathrm{C}\right) \mathrm{dt} ; \\
& \mathrm{A}^{\prime}=\int_{\mathrm{t}}\left(\mathrm{I}_{\text {char }} / \mathrm{R}_{\mathrm{disch}} \mathrm{C}\right) \mathrm{dt} ; \\
& \mathrm{A}=\mathrm{I}_{\text {char }} / \mathrm{R}_{\mathrm{disch}} * \mathrm{C} .
\end{aligned}
$$

Then:

$$
\mathrm{d} \Delta \mathrm{U} / \mathrm{dt}=\mathrm{A}-\Delta \mathrm{U} * \mathrm{U}_{\mathrm{u}} * \mathrm{~K}_{\mathrm{R}}
$$

Linearizing the right side of equation (1), one gets:

$$
\mathrm{d} \Delta \mathrm{U} / \mathrm{dt}=\mathrm{B} * \Delta \mathrm{U}+\mathrm{D}^{*} \mathrm{U}_{\mathrm{u}}
$$

where $\mathrm{B}=-\mathrm{U}_{\mathrm{u}} * \mathrm{~K}_{\mathrm{R}} / \mathrm{R}_{\mathrm{disch}} * \mathrm{C} ; \mathrm{D}=-\Delta \mathrm{Uo} * \mathrm{~K}_{\mathrm{R}} / \mathrm{R}_{\mathrm{disch}}{ }^{*} \mathrm{C}$; $\mathrm{U}_{\mathrm{uo}}, \Delta \mathrm{Uo}$ - coordinates of the point of linearization.

\section{FORMULATION OF THE OPTIMIZATION PROBLEM}

For the object, characterized by equation (8), the control action is subject to the restriction:

Then the optimal control is:

$\mathrm{U}_{\mathrm{U}}^{0}=\left(\mathrm{D} * \mathrm{x}_{0} / \mathrm{L}\right) *\left(\mathrm{e}^{-\lambda 1 * \mathrm{t}}-\mathrm{e} \lambda_{1}^{(2 \mathrm{~T}-\mathrm{t})} /\left(\lambda_{2}\left(1+\mathrm{e}^{\lambda 1(2 * \mathrm{tT})}\right)+\right.\right.$

$+\mathrm{B}\left(1-\mathrm{e}^{\lambda 1(2 * \mathrm{t})}\right)$.

$$
\int_{0}{ }^{t} U_{U}^{2}=\alpha=\text { const. }
$$

It is nesessary to determine optimum control, turning into a minimum of the functional:

$$
\mathrm{J} 1=\int_{0}^{\mathrm{t}}\left(\Delta \mathrm{U}^{2}+\mathrm{L} * \mathrm{U}_{\mathrm{u}}{ }^{2}\right) \mathrm{dt} .
$$

In the future, let:

$$
\begin{aligned}
& \mathrm{x}_{1}=\Delta \mathrm{U} ; \\
& \dot{\mathrm{x}}_{1}=\mathrm{B} * \mathrm{x}_{1}+\mathrm{D} * \mathrm{U}_{\mathrm{u}} \\
& \dot{\mathrm{x}}_{2}=\mathrm{x}_{1}{ }^{2}+\mathrm{L} * \mathrm{U}_{\mathrm{u}}{ }^{2} .
\end{aligned}
$$

Here $\mathrm{x}_{2}$ is the new coordinate, defined by a function:

$$
\mathrm{X}_{2}=\int_{0}^{\mathrm{t}}\left(\mathrm{x}_{1}^{2}+\mathrm{L} * \mathrm{U}_{\mathrm{u}}^{2}\right) \mathrm{dt} \text {. }
$$

Then the Pontryagin function is $\mathrm{p}=\mathrm{x}_{2}\left(\mathrm{t}_{\mathrm{T}}\right)$, when $\mathrm{b}_{1}=0$ and $\mathrm{b}_{2}=1[7,8,10]$.

The Hamilton function for this system is:

$$
\mathrm{H}=\mathrm{p}_{1}\left(\mathrm{~B} * \mathrm{x}_{1}+\mathrm{D} * \mathrm{U}_{\mathrm{u}}\right)+\mathrm{p}_{2}\left(\mathrm{x}_{1}{ }^{2}+\mathrm{L} * \mathrm{U}_{\mathrm{u}}{ }^{2}\right)
$$

Taking the partial derivative of $\mathrm{H}$ at $\mathrm{U}_{\mathrm{u}}$ and equating it to zero, one will get:

$$
\mathrm{P}_{1} * \mathrm{D}+2 * \mathrm{p}_{2} * \mathrm{U}_{\mathrm{u}}=0
$$

Taking into account condition $\mathrm{p}_{\mathrm{n}+1}(\mathrm{t})=\mathrm{p}_{2}(\mathrm{t})=-1[5,9]$, one will get the optimal control action in the form of:

$$
\mathrm{U}_{\mathrm{u}}{ }^{2}=(\mathrm{D} / 2 * \mathrm{~L}) * \mathrm{p}_{1}
$$

Auxiliary variable $\mathrm{p}_{1}$ is determined from the canonical equations, the general expression of which has the form:

$$
\dot{\mathrm{p}}_{\mathrm{i}}(\mathrm{t})=--\mathrm{dH} / \mathrm{dx} ; \dot{\mathrm{x}}_{\mathrm{i}}=\mathrm{dH} / \mathrm{dp}_{\mathrm{i}} \text {. }
$$

These equations describe the conjugated system for the process control.

For the system:

$$
\begin{gathered}
\dot{\mathrm{p}}_{1}=\mathrm{B} * \mathrm{p}_{1}-2 * \mathrm{x}_{1} \\
\dot{\mathrm{x}}_{1}=\mathrm{B} * \mathrm{x}_{1}+\mathrm{D} * \mathrm{U}_{\mathrm{u}}^{2}=\mathrm{B} * \mathrm{x}_{1}+\mathrm{D}^{2} * \mathrm{p}_{1} / 2 * \mathrm{~L},
\end{gathered}
$$

boundary conditions are $\mathrm{x}_{1}(0)=\mathrm{x}_{0} ; \mathrm{p}_{1}\left(\mathrm{t}_{\mathrm{T}}\right)=0$.

Solving equation $(10)$ with respect to $\mathrm{p}_{1}(\mathrm{t})$, one will obtain:

$$
\mathrm{P}_{1}(\mathrm{t})=\left(2 * \mathrm{x}_{0} *\left(\mathrm{e}^{-\lambda 1 * \mathrm{t}}-\mathrm{e}^{\lambda 1 *(2 * \mathrm{t})}\right) / \lambda_{2}\left(1+\mathrm{e}^{\lambda 1(2 * \mathrm{~T})}\right)+\mathrm{B}\left(1-\mathrm{e}^{\lambda 1(2 * \mathrm{tT})}\right)\right.
$$

where $\lambda 1=\sqrt{ }(\mathrm{B} 2 \mathrm{~L}+\mathrm{D} 2) / \mathrm{L}$;

$$
\lambda 2=-\sqrt{ }(\mathrm{B} 2 \mathrm{~L}+\mathrm{D} 2) / \mathrm{L}
$$

Let us note that the optimal control is changed according to the exponential law. 
Lagrange multiplier $\mathrm{L}$ is determined by substituting (11) in limiting condition (9). This task in general is not solved; the numerical solution for a specific object is possible.

Determination of the optimal control algorithm as a function of the state variables requires the computation of $x_{1}(t)$ and eliminating $t$ from the expressions for $x_{1}(t)$ and $U_{u}{ }^{\circ}(t)$. Obviously, the general solution to this problem is extremely difficult.
However, the implementation of such system of feedback control can be performed using the above canonical equations. Measured state variable $\mathrm{x}_{1}$ is supplied to conjugated system (10) which formulates an optimal control action.

The corresponding structural scheme obtains notation (8) and is shown in Fig. 2, where $\mathrm{S}$ is the Laplace operator; $\Delta \mathrm{U}_{\mathrm{u}}$ sensor output difference $\mathrm{U}_{\mathrm{d}}-\mathrm{U}_{\mathrm{d}}{ }^{0}$

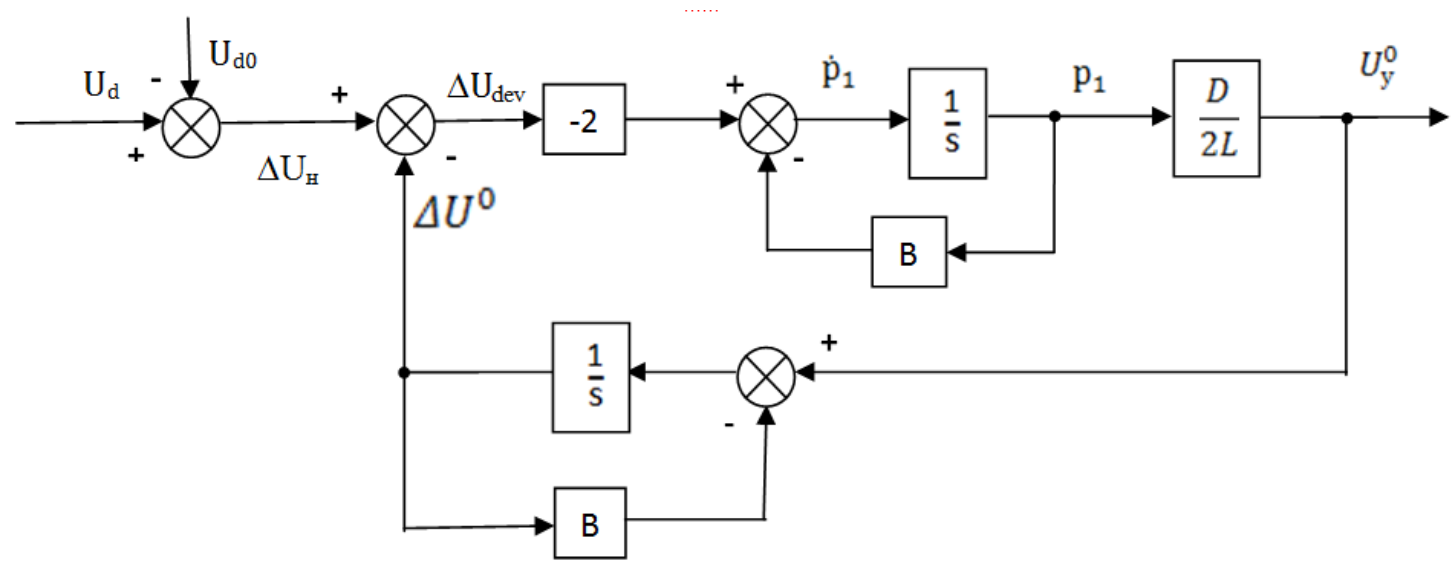

Fig. 2. Structural scheme of the optimal regulator, $\Delta \mathrm{U}_{\mathrm{dev}}$ - deviation of $\Delta \mathrm{U}$ from the optimal values $\Delta \mathrm{U}_{0}$.

The first equation of conjugated system (10) uses the signal of the measured value $\Delta \mathrm{U}_{\mathrm{N}}$ and in accordance with this equation, the upper branch of the diagram gives the value of auxiliary variable $\mathrm{p}_{1}$ and with its help - the optimal value of control signal $\mathrm{U}_{\mathrm{u}}{ }^{\mathrm{o}}$.

The lower branch of the diagram corresponds to the second equation of system (10). Here on the basis of the previously obtained optimal control, an optimal value specifies impact $\Delta \mathrm{U}^{0}{ }_{\text {ref }}$, which is compared with $\Delta \mathrm{U}_{\mathrm{u}}$. The resulting error signal $\Delta \mathrm{U}_{\mathrm{dev}}$ is used in the controller to calculate $\mathrm{U}_{\mathrm{u}}{ }^{\mathrm{o}}$.
To check the effectiveness obtained in the present work, an optimal control modeling system recuperation of braking energy with the optimal controller is used.

The base model was applied and developed in [2]. This model embeds a model of the optimal regulator, shown in figure 3 . The model of the optimal controller is represented by the lower half of figure 3 . The upper half of figure 3 shows the basic elements of the recuperator (a bridge inverter with a control system "Discrete PWM Generator", a condenser and a diode element), and elements of feedback control systems of the inverter recuperator (Ref Ud, Dead Zone, Saturation, Product and others). 


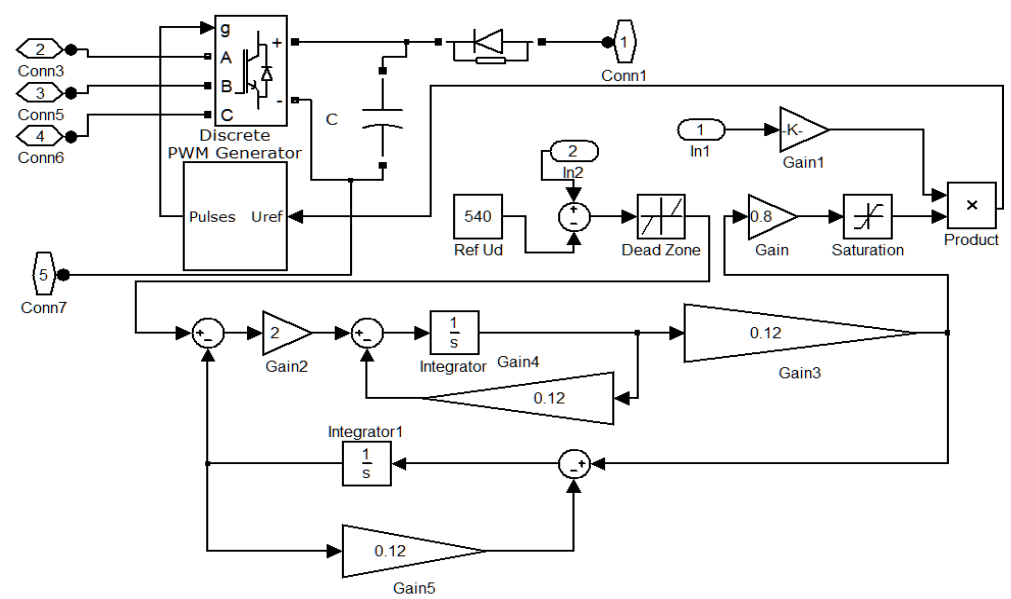

Fig. 3. Model of optimal controller with elements of recuperator.

The simulation results (figure 4) show that the application of the optimal regulator increases the transfer of braking energy to the network on average by $70-80 \%$, compared to the simple proportional control under the same conditions of the train motion.
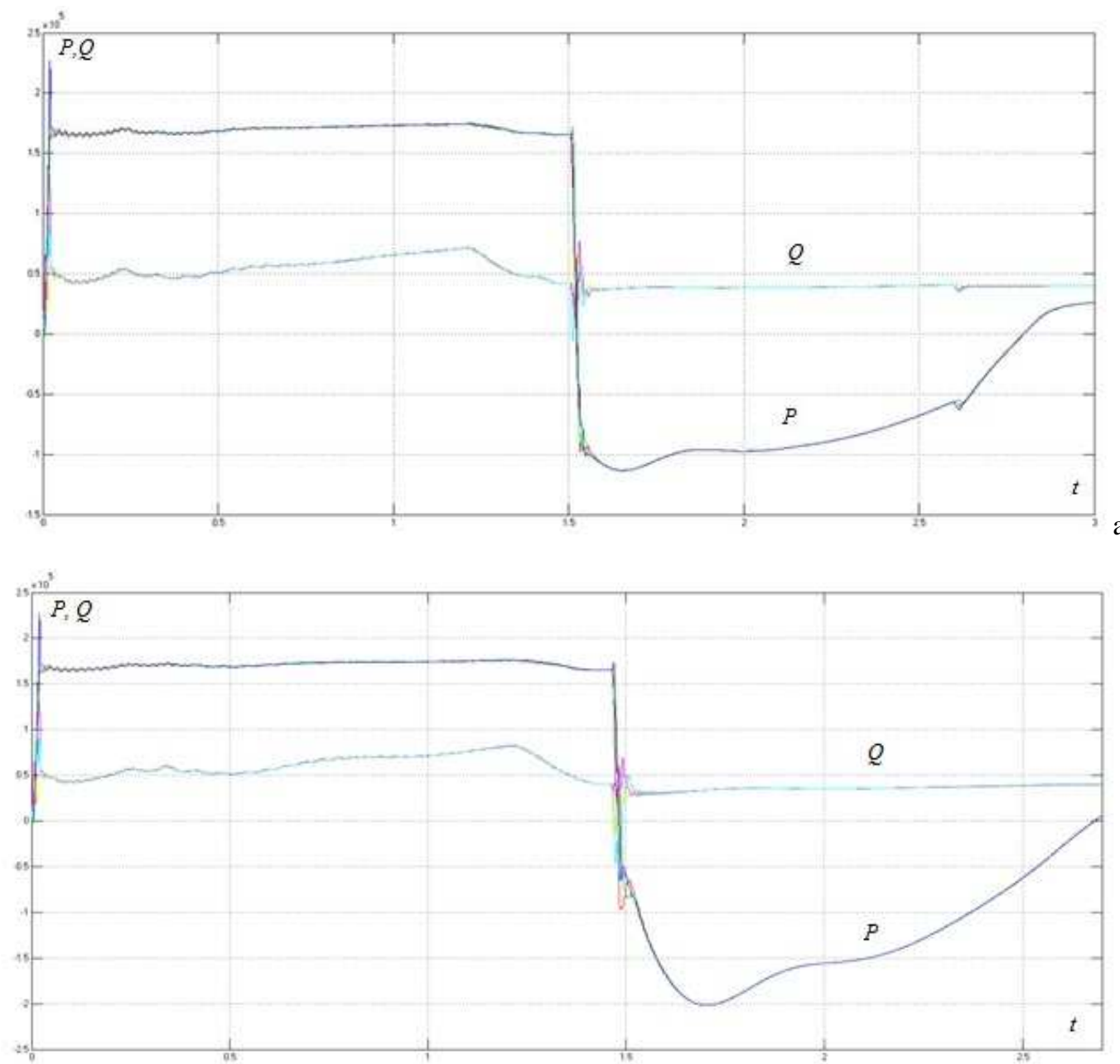

Fig.4. Oscillogram picture of the power exchange with the mains supply. P-active power, Q-reactive power. Negative active power corresponds to the braking mode, a) - for proportional controller, b) - for optimal controller 


\section{CONCLUSION}

Thus, the obtained controller has its own internal loop that helps maintain the value of $\Delta U$ at the optimum level in the process of recovery in the sense of the chosen criterion.

To check the effectiveness obtained in this work, the authors conducted a simulation of the system of traction electric drive with the use of the optimal regulator. The simulation results show that the application of the optimal regulator increases the transmission of braking energy into the power grid on average by $70-80 \%$ compared to the simple proportional control under the same conditions of the train motion (Fig.4).

Further research will be devoted to clarifying the structure and parameters of optimal controller under various conditions of the mains supply, the braking conditions of the train and other factors not considered in the present work.

\section{References}

[1] V. M. Kaveshnikov, E. A. Livanova, "Analysis of possible ways of energy recovery from the underground", Sat.scientific. Tr. The NSTU, Electricity, electromechanics, Electrotechnology,. No7, 2016, pp. 57-66.
[2] V. N. Anosov, V. M. Kaveshnikov, "A simulation model of the process of regenerative braking of the underground train with energy recuperator", Sat.scientific. Tr. The NSTU, Electricity, electromechanics, Electrotechnology, No.8, pp. 111-119, 2016.

[3] L. S. Pontryagin, etc., Mathematical theory of optimal processes, M. Nauka, 1966, pp. 82-96.

[4] A. A. Feldbaum. Foundations of theory of optimal automatic systems, M. Nauka, 1966, pp. 114-145.

[5] Y. Tu. Modern control theory. M. "Engineering", 1971, pp. 259-297.

[6] D. Xue, A. Meyer. Modern automatic control theory and its application,-- M., "Engineering", 1972, pp. 392-425.

[7] I. A. Asnis, A.V. Dmitruk, N. P. Osmolovsky, "The solution using the maximum principle to the problem of the energetically optimal control of the movement of the train", Computational mathematics and mathematical physics, volume 25, number 11, pp. 1644 - 1655, 1985.

[8] K. Ichikawa," Application of optimization theory for bounded state variable problems to the operation of train", Bull. Japan Soc. Math. and Enging, v 11, N 11, pp. $857-865,1968$.

[9] A.E. Bryson and Y.C. Ho, Applied optimal control, Hemisphere/Wiley, 1975, pp. 108-151.

[10] Donald A. Pierre. Optimization theory with applications, Courier Corporation, 1969, pp. 612. 